\title{
Composition, Distribution, and Characterization of Organochlorine Pesticides in Sandstorm Depositions in Beijing, China
}

\author{
S. Fu • K. Li • Z. Z. Yang $\cdot$ X. B. Xu
}

Received: 13 November 2007 / Accepted: 24 March 2008 / Published online: 29 April 2008

(C) Springer Science + Business Media B.V. 2008

\begin{abstract}
Sandstorms which distribute a great number of particles are a special atmospheric occurrence and are uncommon in northern China. This study was conducted to determine, for the first time, the concentration of organochlorine pesticides (OCPs) in sandstorm depositions. Samples were collected from urban areas of Beijing and a total of eight OCPs were measured. All samples contained OCP residues. The total hexachlorocyclohexane ( $\mathrm{HCHs}$ ) concentration ranged from 20.6 to $59.8 \mathrm{ng} \mathrm{g}^{-1}$ and the total dichlorodiphenyltrichloroethane (DDTs) concentration ranged from 12.0 to $14.3 \mathrm{ng} \mathrm{g}^{-1}$. Furthermore, increasing $\mathrm{HCH}$ contamination was observed from the northwest to the southeast and a uniform distribution of DDT contamination was discovered in Beijing. Analysis of the sources of contamination showed that $\mathrm{HCHs}$ in the sandstorm depositions were derived from a relatively old source of lindane, and DDTs mainly originated from an old source of dicofol in Beijing. The preliminary pollution assessment of the samples indicated that $\mathrm{HCH}$ levels might be categorized as low pollution and DDT levels might be
\end{abstract}

S. Fu $\cdot$ K. Li $\cdot$ Z. Z. Yang $\cdot$ X. B. Xu $(\bowtie)$

State Key Laboratory of Environmental Chemistry and Ecotoxicology,

Research Center for Eco-Environmental Sciences, Chinese Academy of Sciences,

P.O. Box 2871, 18 Shuangqing Road, Haidian District,

Beijing, 100085, People's Republic of China

e-mail: xuxb@rcees.ac.cn categorized as no pollution. The present study suggests that sandstorm depositions may not produce the special risk of adverse health effect from OCPs for the residents of Beijing, China.

Keywords China - Deposition .

Dichlorodiphenyltrichloroethanes .

Hexachlorocyclohexanes · Pollution · Sandstorm

\section{Introduction}

Persistent organic pollutants are an important class of organic pollutants which have received considerable attention due to their carcinogenic and mutagenic properties (Blackburn and Kellard 1986; IARC 1987). As a result, some organochlorine pesticides (OCPs) are included in the list of priority pollutants which require monitoring, and researchers have focused their attention on the study of OCPs in recent years (Rauf et al. 2002; Minh et al. 2006; Antunes et al. 2007; Bodin et al. 2007). OCPs have common physicalchemical properties such as semivolatility, high stability, and hydrophobicity, which are favorable for long-range transport and widespread distribution in the environment (Wania and Mackay 1995). OCPs also have known toxic effects on humans and do not degrade to harmless compounds within a few years (Wania and Mackay 1995; Armitage and Gobas 2007). Therefore, international organizations have regulated to reduce or ban the production and usage 
of some OCPs (UNEP 1998; WHO 2000). More information regarding the contamination status of OCPs in sandstorm depositions is therefore needed to better understand their environmental behavior and source-sink relationships.

Long range atmospheric transport and deposition of pollutants are important factors in controlling the regional and global distribution of these pollutants as well as assessing their impact on ecosystems. Furthermore, sandstorms which distribute a great number of particles are a special atmospheric occurrence and are uncommon in northern China. For example, northern China experienced 11 sandstorms in 2006, and one of these sandstorms covered approximately one-eighth of China and deposited about 330,000tons of sand/dust in Beijing (Han et al. 2007; Lin and Chen 2007). The regional characteristics of sand/dust sources are mainly arid or semiarid regions covered by deserts or land undergoing desertification in northern China. Wind-blown sand and floating-dust not only remain in the areas where sandstorms occur, but also extend to neighboring areas. The wind-blown sand extends either northeastward or southeastward, but floating-dust mainly extends southeastward to low-latitude regions such as the East China Plain (Wang et al. 2003). Beijing, the capital of China, is one of the main cities affected by sandstorms, and is one of the most densely populated cities in the world with more than 12 million people. OCPs like hexachlorocyclohexanes (HCHs) and dichlorodiphenyltrichloroethanes (DDTs), can easily accumulate in particles, and these OCPs have been used in large quantities in Beijing for several decades (Lin et al. 2000). This means that sandstorms can have a direct influence on public health, because some of the particles deposited by sandstorms can enter humans via ingestion, inhalation, or dermal routes, etc (De Miguel et al. 1997; Mielke et al. 1999; Madrid et al. 2002). This motivated us to examine the composition, distribution, and characterization of HCHs and DDTs in sandstorm depositions from urban areas of Beijing.

The present study was conducted to investigate the contamination status of HCHs and DDTs in sandstorm depositions from urban areas of Beijing. Our approach was to provide information on the extent of HCHs and DDTs contamination in urban areas of Beijing, to determine the spatial distribution of these OCPs, to identify the possible sources of pollution, and to explore possible factors affecting contamina- tion in order to prevent further environmental deterioration in Beijing.

\section{Materials and Methods}

\subsection{Samples}

A serious sandstorm developed from the Mongolian cyclone and blew over Beijing on April 16, 2006 (Han et al. 2007; Lin and Chen 2007). The climate in Beijing at that time was dominated by temperate semi-wet monsoon conditions, with a mean temperature of $14^{\circ} \mathrm{C}$ during the sampling period. It has been reported that OCP contamination level is less during this season ( $\mathrm{Li}$ et al. 2007), so the sandstorm deposition samples were regarded as representative of light pollution. Sandstorm deposition samples were obtained from ten urban sites in Beijing, China, (Fig. 1) on 17 April, 2006. The total sampling region consisted of an area of $750 \mathrm{~km}^{2}$. All samples were collected from a platform $0.5-1.0 \mathrm{~m}$ in height during daytime (between 8:00A.M. and 6:00P.M.) on days with no precipitation. The collected samples were composites of three sub-samples obtained at each sampling site. The gathered samples were transferred to precleaned amber glass bottles and were stored at $4{ }^{\circ} \mathrm{C}$. Extraction was normally carried out within $72 \mathrm{~h}$.

The particle size distributions of the dry deposition samples were analyzed using a Laser Particle Size Analyzer (Mastersizer 2000, Malvern Co., UK), when the particles suspended in water.

\subsection{Chemicals}

The mixed OCPs standard solution $\left(100 \mu \mathrm{g} \mathrm{ml}^{-1}\right)$ included $\alpha-\mathrm{HCH}, \beta-\mathrm{HCH}, \gamma-\mathrm{HCH}, \delta-\mathrm{HCH}, \mathrm{pp}^{\prime}$-DDT, pp'-DDD, $\mathrm{pp}^{\prime}$-DDE and op'-DDT and was purchased from the National Research Center for Certified Reference Materials of China. 2,4,5,6-tetrachloro-mxylene (TCMX) as a surrogate was purchased from Supelco (Bellefonte, PA, USA). The standards were further diluted to the desired concentration with isooctane and used as working standards. Florisil (60-100 mesh) was purchased from Supelco (Bellefonte, PA, USA) and was activated in a drying oven at 130 for 16h. Anhydrous sodium sulfate (Beijing Chemical Factory, China) was heated at 600 for $12 \mathrm{~h}$ before use to destroy organic contamination. All 
Fig. 1 Sampling sites of sandstorm deposition in urban areas of Beijing

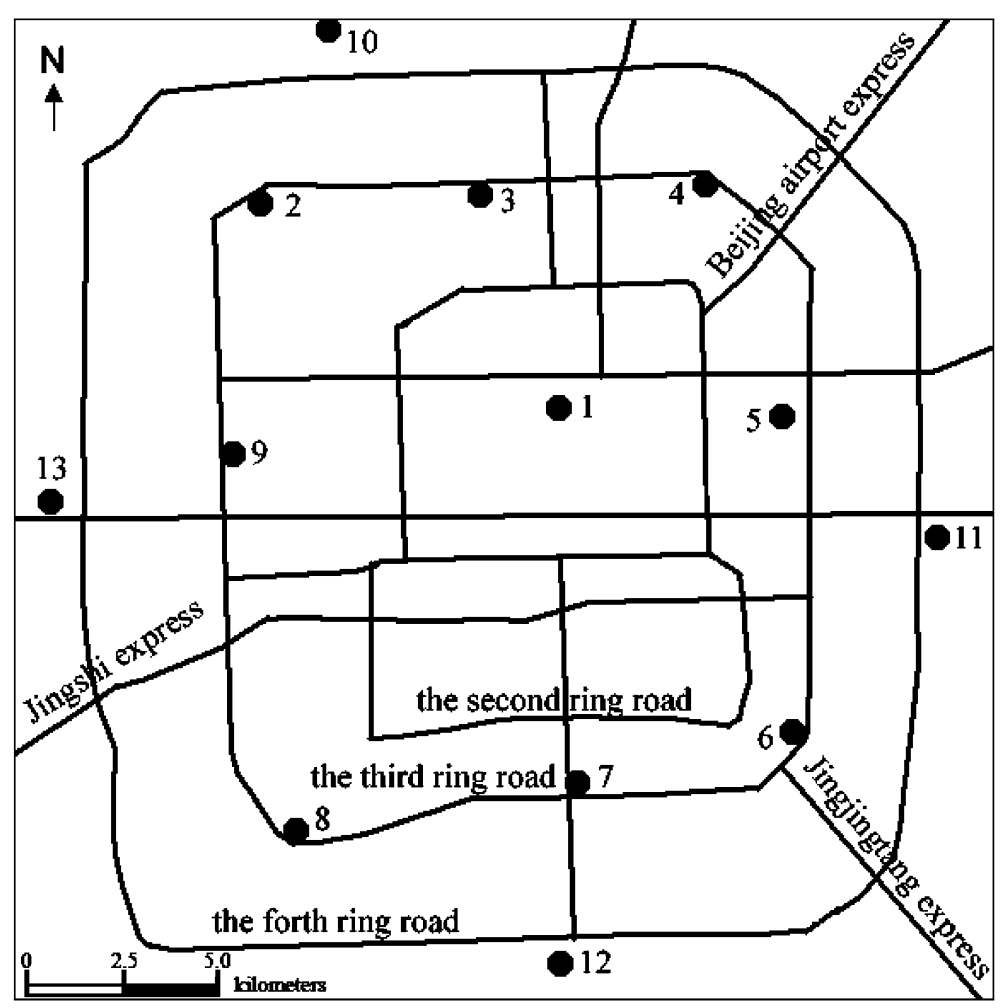

solvents used were of pesticide grade (J. T. Baker, USA).

\subsection{Extraction and Cleanup}

Five grams of each sandstorm deposition sample was weighed then ground with anhydrous sodium sulfate into a free-flowing powder. The samples were extracted with $30 \mathrm{ml}$ of hexane/acetone $(1: 1, v / v)$ by ultrasonication for $4 \mathrm{~min}$ then separated by centrifugation. This process was repeated three times. Before extraction, TCMX was added as a surrogate standard. The concentrated extracts were evaporated to $1 \mathrm{ml}$ in the Kuderna-Danish concentrator ( $\mathrm{K}-\mathrm{D}$ concentrator) under a gentle $\mathrm{N}_{2}$ stream for cleanup.

HCHs and DDTs were cleaned up using a chromatography column $(30 \mathrm{~cm} \times 10 \mathrm{~mm}$ i.d. $)$ containing $4 \mathrm{~g}$ of activated florisil and $2 \mathrm{~g}$ of anhydrous sodium sulfate. The column was pre-eluted with $40 \mathrm{ml}$ of hexane/diethyl ether $(4: 1, v / v)$ before loading the sample. The fraction containing HCHs and DDTs was eluted using $60 \mathrm{ml}$ of hexane/diethyl ether $(4: 1, v / v)$.
The solvent was evaporated to $100 \mu \mathrm{l}$ in the $\mathrm{K}-\mathrm{D}$ concentrator under a gentle $\mathrm{N}_{2}$ stream for analysis.

\subsection{Analyses}

Analyses of HCHs and DDTs were carried out using an Agilent 6890 gas chromatograph (GC) equipped with a micro-cell ${ }^{63} \mathrm{Ni}$ electron capture detector. Separation was performed on a $30 \mathrm{~m}$ DB-5MS $(30 \mathrm{~m} \times$ $0.25 \mathrm{~mm}$ i.d., $0.25 \mu \mathrm{m}$ film thickness) capillary column. The injector and detector temperatures were $230^{\circ} \mathrm{C}$ and $305^{\circ} \mathrm{C}$, respectively. The GC column was maintained at $100^{\circ} \mathrm{C}$ for $2 \mathrm{~min}$, then increased by $10^{\circ} \mathrm{C} \mathrm{min}{ }^{-1}$ to $160^{\circ} \mathrm{C}$, further increased by $4^{\circ} \mathrm{C} \mathrm{min}^{-1}$ to $230^{\circ} \mathrm{C}$, and finally increased by $10^{\circ} \mathrm{C} \mathrm{min}^{-1}$ to $280^{\circ} \mathrm{C}$ and held at this temperature for $10 \mathrm{~min}$. The total run time was $40.5 \mathrm{~min}$. Quantification of the samples was performed using an external standard method.

To confirm the OCP results, selected typical samples were checked using an Agilent 6890 series gas chromatograph coupled to an Agilent 5973 mass spectrometer (MS) using an electron impact ioniza- 
tion source (EI) in the selected ion monitoring mode. In EI mode, the MS source temperature was $230^{\circ} \mathrm{C}$, the transfer line was $300^{\circ} \mathrm{C}$ and the electron energy was $70 \mathrm{eV}$. Gas chromatographic separation was performed as mentioned above. The GC-MS parameters are shown in Table 1.

\subsection{Quality Control}

A laboratory method blank was run to demonstrate lack of interference and cross-contamination. In addition, a procedural blank was run in parallel with every set of six samples to further check for interference and cross-contamination. Duplicate samples were analyzed in the laboratory along with regular samples as an additional quality control assessment to ensure valid results. Instrument stability and relative response factor variance were determined by analyzing the calibration standard solutions in each sample batch.

Identification of HCHs and DDTs were confirmed, and concentrations were measured using an external quantification standard consisting of known amounts of all the target compounds. For accuracy and precision of analysis, method blanks were run first using the same solvents used for real samples. No contaminants of OCPs were found in the method blanks $(n=3)$. The average recovery experiments were carried out in triplicate by spiking known concentrations of standards in a matrix blank. The limits of detection were calculated as three times the response of the signal-to-noise $(\mathrm{S} / \mathrm{N})$ ratio and the limits of quantification were calculated as five times the $\mathrm{S} / \mathrm{N}$ ratio. These parameters are shown in Table 2. At the same time, prior to extraction, each of the soil samples was spiked with a known concentration of TCMX as a surrogate to compensate for the loss of components. The recoveries of the TCMX surrogate were in the range $70-90 \%$. The recoveries of the surrogate were satisfactory and no correlation of analytical data was applied to the samples.

\subsection{Statistics}

Statistical analysis was carried out using SPSS 13.0 for Windows. Principal component analysis (PCA), a multivariate statistical technique, was used to derive new components (principal components) as a linear combination of the original variables, while principal components (PCs) attempted to preserve the statistical relationships present in the original data. In the present study, inter-species variations in $\mathrm{HCHs}$ and DDTs were investigated using PCA. Initial variables considered were the concentration values of $\mathrm{HCHs}$ and DDTs. Values of HCHs and DDTs were normalized to a percent of the sum of all congeners, respectively. Rotation was used in the PCA using the varimax method to facilitate interpretation of the results.

\section{Results and Discussion}

\subsection{HCHs}

\subsubsection{HCH Composition}

$\mathrm{HCHs}$ were identified in all of the sandstorm deposition samples. The total $\mathrm{HCH}$ concentration (equivalent sum of $\alpha-\mathrm{HCH}+\beta-\mathrm{HCH}+\gamma-\mathrm{HCH}+\delta-$ $\mathrm{HCH}$ ) ranged from 20.6 to $59.8 \mathrm{ng} \mathrm{g}^{-1}$ (median 28.9ng $\mathrm{g}^{-1}$, dry weight). The highest concentration
Table 1 Acquisition data for GC-MS analysis of OCPs including a surrogate standard using SIM mode, two selected ions for each compound

\begin{tabular}{llll}
\hline Compound & Retention time (min) & $\begin{array}{l}\text { Characteristic fragment } \\
\text { ions MS-1 }\end{array}$ & $\begin{array}{l}\text { Characteristic fragment } \\
\text { ions MS-2 }\end{array}$ \\
\hline TCMX & 15.37 & 207 & 209 \\
$\alpha-\mathrm{HCH}$ & 16.95 & 183 & 181 \\
$\beta$-HCH & 18.00 & 183 & 181 \\
$\gamma$-HCH & 18.30 & 183 & 181 \\
$\delta$-HCH & 19.24 & 183 & 181 \\
pp'-DDE & 27.37 & 246 & 248 \\
pp'-DDD & 29.24 & 235 & 165 \\
op'-DDT & 29.76 & 235 & 165 \\
pp'-DDT & 32.01 & 235 & 165 \\
\hline
\end{tabular}


Table 2 Limits of detection, limits of quantification, recoveries and relative standard deviations (RSD\%) from sandstorm deposition samples

\begin{tabular}{|c|c|c|c|c|c|c|c|c|}
\hline & $\alpha-\mathrm{HCH}$ & $\beta-\mathrm{HCH}$ & $\gamma-\mathrm{HCH}$ & $\delta-\mathrm{HCH}$ & $\mathrm{Pp}^{\prime}-\mathrm{DDE}$ & $\mathrm{pp}^{\prime}-\mathrm{DDD}$ & op'-DDT $^{\prime}$ & $\mathrm{pp}^{\prime}$-DDT \\
\hline LODs (ng g ${ }^{-1}$ ) & 0.13 & 0.02 & 0.76 & 0.13 & 0.23 & 0.01 & 0.06 & 0.06 \\
\hline LOQs (ng g $\left.{ }^{-1}\right)$ & 0.22 & 0.03 & 1.27 & 0.22 & 0.38 & 0.02 & 0.10 & 0.10 \\
\hline Recoveries (\%) & 70.4 & 85.6 & 77.0 & 75.7 & 87.3 & 72.1 & 89.7 & 90.0 \\
\hline $\mathrm{RSD} \%$ & \pm 5 & \pm 7 & \pm 3 & \pm 7 & \pm 3 & \pm 5 & \pm 7 & \pm 6 \\
\hline
\end{tabular}

was found at site $7\left(56.9 \mathrm{ng} \mathrm{g}^{-1}\right)$ and the lowest value was found at site $9\left(20.6 \mathrm{ng}^{-1}\right)$. Since sandstorm depositions have a direct influence on surface soil, we further compared the soil concentration of $\mathrm{HCHs}$ reported elsewhere in the literature. In comparison with other areas of China, the concentration of $\Sigma \mathrm{HCH}$ in Beijing was higher than those in the soils from Guangting Reservoir (N.D. $-9.0 \mathrm{ng} \mathrm{g}^{-1}$ ) which is located in northwest Beijing with fewer anthropogenic activities (Zhang et al. 2005), but was similar to those in agricultural surface soils from greenhouses in suburban areas of Beijing (15.8 $\pm 6.0 \mathrm{ng} \mathrm{g}^{-1}$; Ma et al. 2003). The median value was similar to that from urban and rural soils in Tianjin, a city adjacent to Beijing with recent production and usage of $\mathrm{HCHs}$ (45.8ng g ${ }^{-1}$; Gong et al. 2004) and that from rice soils in Jiaxing, a famous agricultural area in China (18.655.4ng g ${ }^{-1}$; Zhao et al. 2002). Compared to urban soils from some developed countries, the levels were similar to those in Romania $\left(29.2 \pm 27.1 \mathrm{ng} \mathrm{g}^{-1}\right.$; Covaci et al. 2001) and Poland $\left(11 \pm 29 \mathrm{ng} \mathrm{g}^{-1}\right.$; Falandysz et al. 2001). In contrast to some developing countries in tropical/subtropical areas where pollutants easily evaporate from soil, the levels were much higher than those in urban soils from India (N.D. -3.6ng $\mathrm{g}^{-1}$; Kawano et al. 1992) and Egypt (N.D. $-16.2 \mathrm{ng} \mathrm{g}^{-1}$; Kabbany et al. 2000). Furthermore, it could be also seen that the median level of HCHs (28.9ng $\mathrm{g}^{-1}$ ) was much higher than that in pristine areas of the Tibetan plateau in China $\left(0.18-5.38 \mathrm{ng} \mathrm{g}^{-1}\right.$; Fu et al. 2001).

\subsubsection{HCH Distribution}

The distribution of $\mathrm{\Sigma HCHs}$ in the sandstorm deposition samples is shown in Fig. 2, which reveals an
Fig. 2 The distribution of $\Sigma \mathrm{HCHs}$ in urban areas of Beijing (data in the figure are in nanogram per gram)

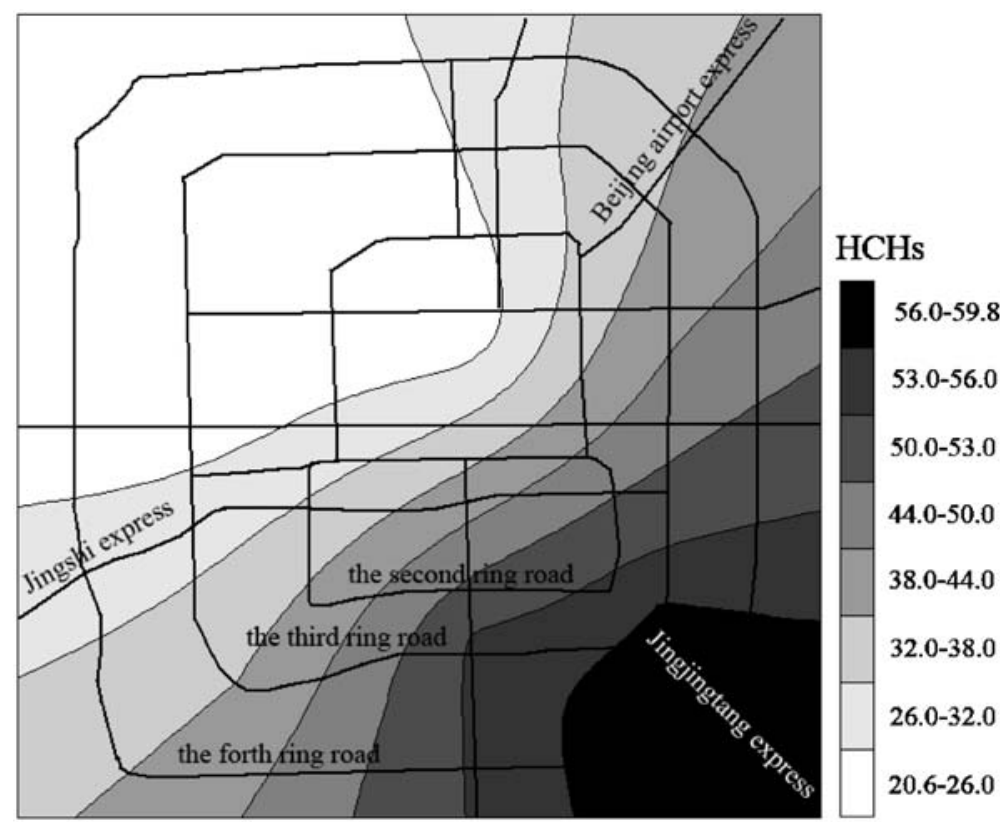


increasing trend from northwest to southeast Beijing. It is interesting to explore a correlation between $\Sigma \mathrm{HCHs}$ and the minimum particle size of the dry deposition samples. The particle size distributions of the dry deposition samples were analyzed using a Laser Particle Size Analyzer; the relevant data are shown in Table 3. A slight correlation existed between $\mathrm{SHCHs}$ and minimum particle size $(r=$ $0.16, p<0.05)$. This indicated that the $\Sigma \mathrm{HCHs}$ were partially associated with particle size distribution and that they were removed through the scavenging of particulates. The wind direction during the sandstorm was northwest in Beijing, and the wind speed was gentle. A huge deposition of approximately $20 \mathrm{~g} / \mathrm{m}^{2}$ over a $304,000 \mathrm{~km}^{2}$ area of Beijing was observed (Wang et al. 2003; Han et al. 2007; Lin and Chen 2007). In the slow-motion process, HCHs could be absorbed by smaller particles passing though the urban area, transported slowly and deposited in the southeast area of Beijing, partially resulting in higher concentrations in this area. Another possible reason is the distribution of the industrial zone which is mainly located in the southeast area of Beijing. The contamination of the industrial zone with $\mathrm{HCHs}$ was probably higher than other sites in Beijing. These factors could possibly explain the increased tendency of contamination from northwest to southeast in the urban areas of Beijing.

\subsubsection{HCHs Profiles}

PCA was performed to evaluate similarities or differences between the $\mathrm{HCH}$ congener patterns of each

Table 3 Particle size distributions of Beijing deposition samples

\begin{tabular}{lccc}
\hline \multirow{2}{*}{ Sample number } & \multicolumn{3}{c}{$<$ Particle size (particle number \%) $(\mu \mathrm{m})$} \\
\cline { 2 - 4 } & $<\mathrm{d} 1(10 \%)$ & $<\mathrm{d} 2(50 \%)$ & $<\mathrm{d} 3(90 \%)$ \\
\hline 1 & 11.3 & 34.6 & 80.3 \\
2 & 11.2 & 33.3 & 73.1 \\
3 & 12.6 & 38.7 & 110.1 \\
4 & 10.6 & 39.0 & 104.9 \\
5 & 9.0 & 35.8 & 100.4 \\
6 & 10.2 & 31.7 & 69.5 \\
7 & 13.78 & 39.9 & 88.3 \\
8 & 12.0 & 37.5 & 83.8 \\
9 & 12.1 & 35.8 & 82.0 \\
10 & 9.2 & 32.7 & 85.4 \\
\hline
\end{tabular}

sample, all data were normalized to a percent of the sum of HCHs. PCs were determined by eigenvalues of over 1. Two extracted PCs could explain $87.5 \%$ of the data variance. A loading plot and score plot rotation were obtained using the varimax method (Fig. 3). PC1 in Fig. 3a accounted for $49.8 \%$ of the total variance and was characterized by $\beta-\mathrm{HCH}$ and $\delta-\mathrm{HCH}$, while PC2 in Fig. $3 \mathrm{~b}$ accounted for $37.7 \%$ of the total variance and was characterized by $\alpha-\mathrm{HCH}$ and $\gamma-\mathrm{HCH}$. The PCA results indicate that the compositions of $\mathrm{HCHs}$ in the Beijing samples were similar, possibly originating from the same source.

When considering composition patterns, the ratio of $\alpha-\mathrm{HCH} / \gamma-\mathrm{HCH}$ is relatively stable with a value of 4.64 5.83 for the technical HCHs and nearly zero for lindane (Zhang et al. 2004; Gong et al. 2004), and can be used to monitor whether the source was from technical HCHs or lindane (Kim et al. 2002). In the present study, the ratio of $\alpha-\mathrm{HCH} / \gamma-\mathrm{HCH}$ varied from 0.57 to 0.64 , in addition, $\alpha-\mathrm{HCH}$ can be transported great distances through the atmosphere, indicating the presence of a potential emission source of lindane (Brubaker and Hites 1998). Compared with the fraction of $\beta$-HCHs in technical HCHs (5-14\%; Qiu et al. 2004), the relatively high percentage of $\beta$-HCHs means that there was a lack of new $\mathrm{HCH}$ sources in the studied areas. In the present study, $\beta-\mathrm{HCH}$ was the major contributing compound in most of the samples and accounted for $20.5-39.6 \%$. It could be concluded that $\mathrm{HCHs}$ in sandstorm depositions from urban areas of Beijing might originate from a relatively old source of lindane.

\subsection{DDTs}

\subsubsection{DDT Composition}

DDTs were identified in all of the sandstorm deposition samples. The total DDT content (equivalent sum of $\mathrm{pp}^{\prime}$-DDT + $\mathrm{pp}^{\prime}$-DDD + pp'-DDE + op'-DDT) ranged from 12.0 to $14.3 \mathrm{ng} \mathrm{g}^{-1}$ (median $12.8 \mathrm{ng} \mathrm{g}^{-1}$, dry weight). The highest concentration was found at site $2\left(14.3 \mathrm{ng} \mathrm{g}^{-1}\right)$ and the lowest value was found at site $1\left(12.0 \mathrm{ng} \mathrm{g}^{-1}\right)$. Since sandstorm depositions have a direct influence on surface soil, we compared the soil concentrations of DDTs reported elsewhere in the literature. In comparison with other areas of China, the concentration of $\mathrm{EDDT}$ in sandstorm depositions in Beijing was much lower than those in agricultural surface soils from greenhouses in suburban areas of 
Fig. 3 a Loading plot of PCA based on the normalized data for HCHs; b Score plot of PCA based on the normalized data for HCHs
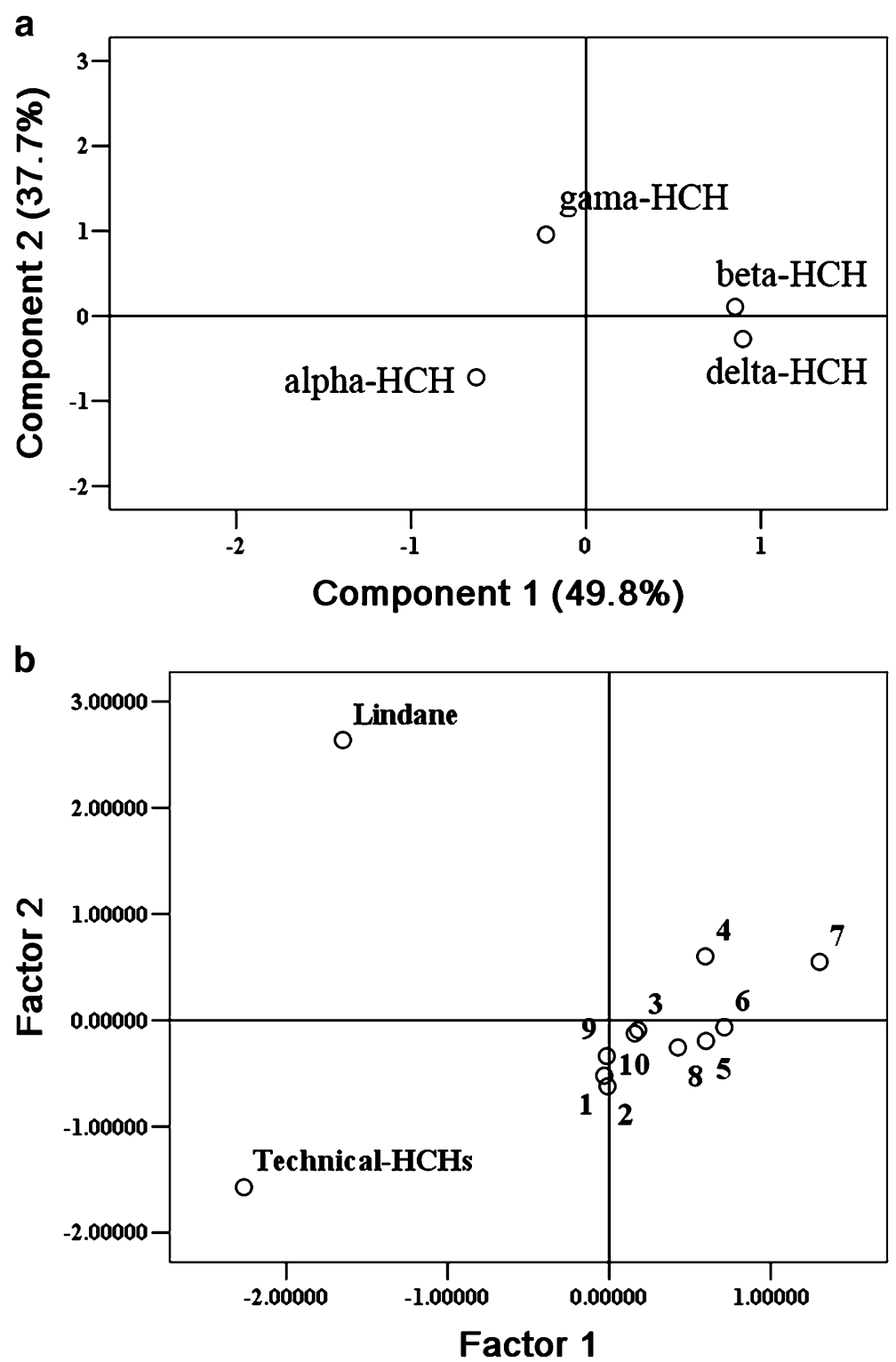

Beijing (64.4 $\pm 30.4 \mathrm{ng} \mathrm{g}^{-1}$; Ma et al. 2005), and the median value was slightly higher than that in soils from the Guangting Reservoir located in the exurb of Beijing with fewer anthropogenic activities (median: $5.11 \mathrm{ng} \mathrm{g}^{-1}$;Zhang et al. 2005). Furthermore, the levels were lower than those from urban and rural soils in Tianjin, one of the neighboring cities of Beijing $\left(49.6 \pm 126.8 \mathrm{ng} \mathrm{g}^{-1}\right.$; Gong et al. 2004) and those from rice soils in Jiaxing, a famous agricultural area in China (28.6-71.8ng g ${ }^{-1}$; Zhao et al. 2002). Compared to urban soils from some developed countries, the levels were considerably lower than those in Romania $\left(226.9 \pm 157.2 \mathrm{ng} \mathrm{g}^{-1}\right.$; Covaci et al.
2001) and Poland $\left(110 \pm 89 \mathrm{ng} \mathrm{g}^{-1}\right.$; Falandysz et al. 2001). In contrast to developing countries in tropical/ subtropical areas where pollutants easily evaporate from soil, the levels were much higher than those in Egypt (N.D.; Kabbany et al. 2000). It was also seen that the median level of DDTs $\left(12.8 \mathrm{ng} \mathrm{g}^{-1}\right)$ was much higher than that in pristine areas of the Tibetan plateau in China (N.D. $-2.83 \mathrm{ng} \mathrm{g}^{-1}$; Fu et al. 2001).

\subsubsection{DDT Distribution}

The levels of $\Sigma$ DDTs in sandstorm deposition samples ranged from 12.0 to $14.3 \mathrm{ng} \mathrm{g}^{-1}$ (median 
12.8ng g ${ }^{-1}$, dry weight). These differences in concentration might be neglected when we took into account the errors of measurement, extraction and cleanup etc. This result indicated that the distribution of DDTs in sandstorm depositions in Beijing is much more uniform, and a possible reason for this may be due to the smaller area studied in the present study.

\subsubsection{DDT Profiles}

PCA was performed to evaluate similarities or differences between the DDT congener patterns of each sample. All data were normalized to a percent of the sum of DDTs. PCs were determined by eigenvalues of over 1. Two extracted PCs could explain $75.9 \%$ of the data variance. A loading plot and score plot rotation were obtained using the varimax method (Fig. 4). $\mathrm{PC} 1$ in Fig. $4 \mathrm{a}$ accounted for $49.2 \%$ of the total variance and was characterized by $\mathrm{pp}^{\prime}-\mathrm{DDE}$ and $\mathrm{pp}^{\prime}-$ DDD, while PC2 of Fig. $4 b$ accounted for $29.7 \%$ of the total variance and was characterized by op'-DDT and $\mathrm{pp}^{\prime}-\mathrm{DDT}$. The PCA results indicated that the composition of DDTs in most samples (except site 1) was generally similar, and DDTs in the depositions investigated might originate from the same source.

The ratio of $\mathrm{op}^{\prime}-\mathrm{DDT} / \mathrm{pp}^{\prime}$-DDT was used to distinguish DDT pollution caused by technical DDTs from that by dicofol (Qiu et al. 2005). Since op'-DDT
Fig. 4 a Loading plot of PCA based on the normalized data for DDTs; b Score plot of PCA based on the normalized data for DDTs

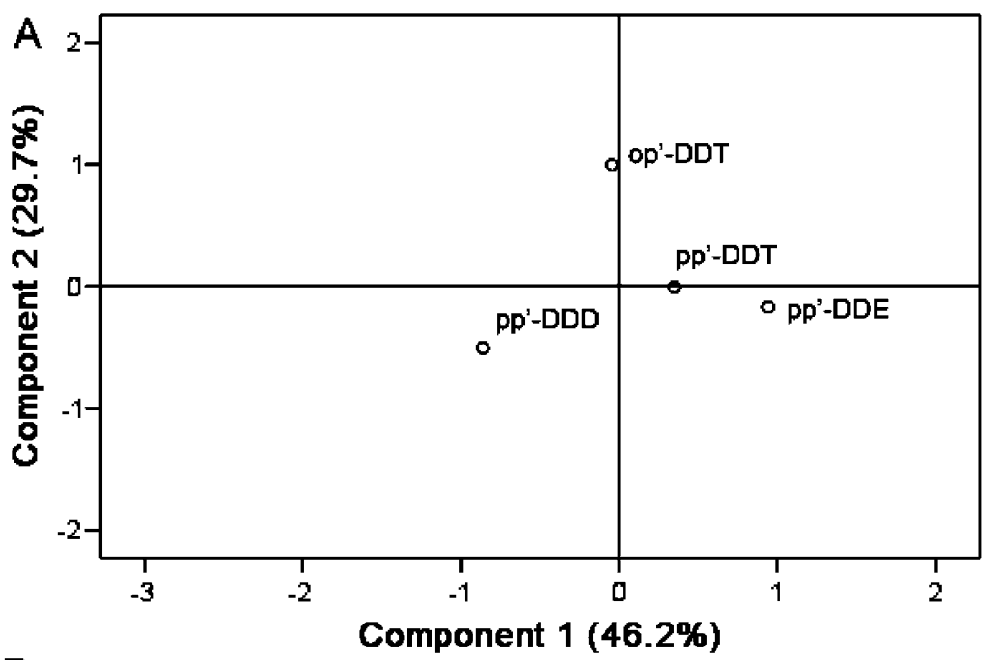

B

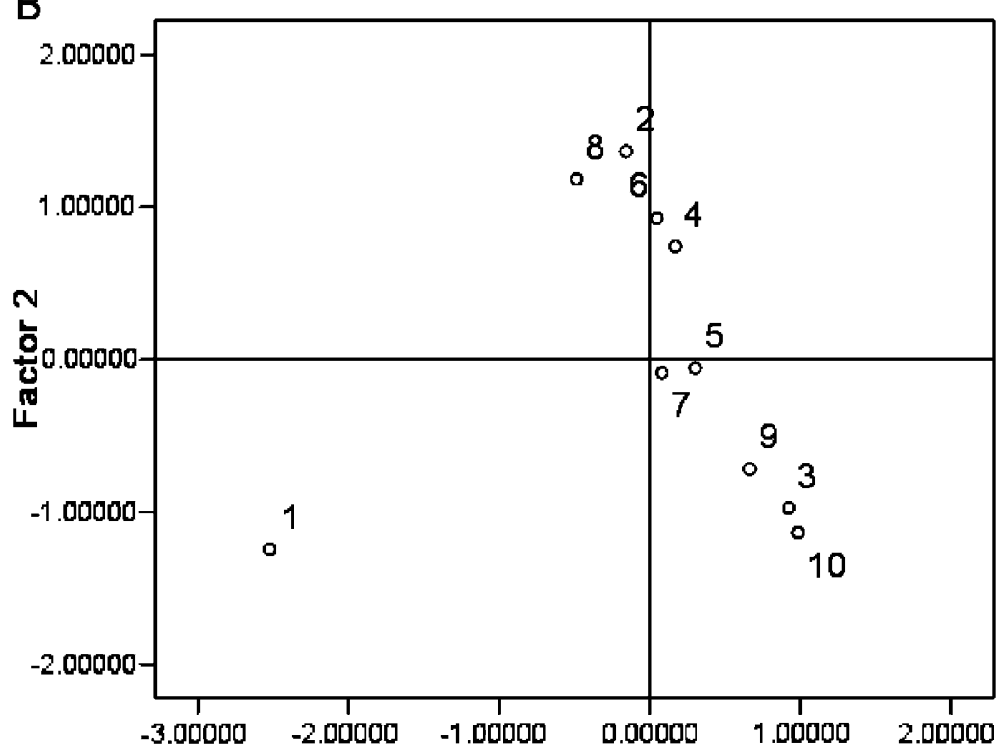

Factor 1 
is more unstable than $\mathrm{pp}^{\prime}$-DDT in the environment, it would be impossible for the ratio of $\mathrm{op}^{\prime}-\mathrm{DDT} / \mathrm{pp}^{\prime}$ DDT to be higher than technical DDTs, whereas the characteristics of pollution from dicofol would have a higher op'-DDT/pp'-DDT ratio than that of technical DDTs. It is well-known that dicofol contains approximately $3-7 \%$ DDTs as impurities. Generally, the ratio of $\mathrm{op}^{\prime}-\mathrm{DDT} / \mathrm{pp}^{\prime}$-DDT ranges from 0.2 to 0.3 in technical DDTs and from 1.3 to 9.3 or higher in dicofol (Qiu et al. 2005). In the present study, the ratio varied from 6.0 to 14.8 , with 11.8 as the median, which outlined the important contribution of dicofol. When considering composition patterns, the ratio of (pp'-DDE + pp'-DDD)/pp'-DDT can be used as an indicator of the residence time of $\mathrm{pp}^{\prime}$-DDT in the environment, because the levels of the parent compounds ( $\mathrm{pp}^{\prime}$-DDT) in the natural environment decrease with time and the major metabolites are expected to be $\mathrm{pp}^{\prime}$-DDE and $\mathrm{pp}^{\prime}$-DDD (Qiu et al. 2004). A ratio $>1$ is generally expected for old sources in the environment and a ratio $<1$ indicates relatively recent exposure to the parent DDT (Jaga and Dharmani 2003). In the present study, the ratios of ( $\mathrm{pp}^{\prime}$-DDE $+\mathrm{pp}^{\prime}$-DDD)/pp'-DDT were $>1$ in all samples, which meant that the contamination by dicofol occurred in the past. It could be concluded that DDTs in the sandstorm depositions from urban areas of Beijing might originate from a relatively old source of dicofol.

\subsection{Pollution Assessment}

According to the guidelines of the Chinese environmental quality standard for soil (GB15618-1995), the quality of soil is classified as having no pollution, low pollution, middle pollution and high pollution. If the pollution level is below grade I, it is defined as no pollution; if the pollution level is between grade I and grade II, it is defined as low pollution, and so on. For $\mathrm{HCH}$, the median value for all samples was lower than the maximum allowable concentration of class I soil in China (50 $\mathrm{ng} \mathrm{g}^{-1}$, the guidelines of Chinese environmental quality standard for soil, GB156181995). This might be attributed to the banned usage of industrial HCHs for almost 30 years. However, two sample sites were defined as low pollution, and an increasing tendency of $\mathrm{HCHs}$ from northwest to southeast in Beijing are a cause for concern. For DDTs, the median value for all samples was much lower than the maximum allowable concentration of class I soil in China (50 $\mathrm{ng} \mathrm{g} \mathrm{g}^{-1}$, the guidelines of Chinese environmental quality standard for soil, GB15618-1995). This might be attributed to the banned usage of DDTs in China for nearly 30 years. However, the half-life of pp'-DDT in soil is longer than 15 years (Qiu et al. 2004), and DDT together with its metabolites can act as endocrine disruptors (Blackburn and Kellard 1986; IARC 1987), therefore it is necessary to monitor the status of DDTs continuously.

\section{Conclusion}

The present work investigated the composition, distribution and characterization of $\mathrm{HCHs}$ and DDTs in sandstorm depositions from urban areas in Beijing. The results indicated that $\mathrm{HCH}$ levels might be categorized as no or low pollution and DDT levels might be categorized as no pollution. There was an increasing trend of $\mathrm{HCHs}$ concentrations from northwest to southeast and a uniform distribution of DDTs in urban areas of Beijing. HCHs in sandstorm depositions might originate from a relatively old source of lindane. Dicofol was an important old source of contamination in the sandstorm depositions in Beijing. However, two sample sites containing $\mathrm{HCH}$ were defined as low pollution, and the increasing tendency of $\mathrm{HCHs}$ from northwest to southeast in Beijing are a cause for concern. These findings are important and can be used to control the pollution source of OCPs and enhance urban environmental quality in Beijing. Therefore, the present study enhances awareness of the attention that should be paid to the quality of the urban environment during sandstorms to maintain human health and environmental safety.

Acknowledgements This study was supported by the National Natural Scientific Foundation of China (No. 20707031 and No. 20437020).

\section{References}

Antunes, P., Gil, O., Ferreira, M., Vale, C., \& Reis-Henriques, M. A. (2007). Depuration of PCBs and DDTs in mullet under captivity clean conditions. Chemosphere, 67, S58-S64.

Armitage, J. M., \& Gobas, F. A. P. C. (2007). A terrestrial foodchain bioaccumulation model for POPs. Environmental Science \& Technology, 41, 4019-4025.

Blackburn, G. M., \& Kellard, B. (1986). Chemical carcinogensPart II. Chemical Industry, 20, 687-695. 
Bodin, N., Abarnou, A., Le Guellec, A. M., Loizeau, V., \& Philippon, X. (2007). Organochlorinated contaminants in decapod crustaceans from the coasts of Brittany and Normandy (France). Chemosphere, 67, S36-S47.

Brubaker, W. W., \& Hites, R. A. (1998). OH Reaction Kinetics of Gas-Phase <alpha>- and < gamma>-hexachlorocyclohexane and hexachlorobenzene. Environmental Science \& Technology, 32, 766-769.

Covaci, A., Hura, C., \& Schepens, P. (2001). Selected persistent organochlorine pollutants in Romania. Science of the Total Environment, 280, 143-152.

De Miguel, E., Llamas, J. F., Chacon, E., Berg, T., Larssen, S., Royset, O., et al. (1997). Origin and patterns of distribution of trace elements 540 in street dust: unleaded petrol and urban lead. Atmospheric Environment, 31, 2733-2740.

Falandysz, J., Brudnowska, B., Kawano, M., \& Wakimoto, T. (2001). Polychlorinated biphenyls and organochlorine pesticides in soils from the southern part of Poland. Archives of Environmental Contamination and Toxicology, 40, 173-178.

Fu, S., Chu, S. G., \& Xu, X. B. (2001). Organochlorine pesticide residue in soils from Tibet, China. Bulletin of Environmental Contamination and Toxicology, 66, 171-177.

Gong, Z. M., Xu, F. L., Dawson, R., Cao, J., Liu, W. X., Li, B. G., et al. (2004). Residues of hexachlorocyclohexane isomers and their distribution characteristics in soils in the Tianjin area, China. Archives of Environmental Contamination and Toxicology, 46, 432-437.

Han, T., Lin, J., Wang, Y., Zheng, B., Song, H., Liu, J., et al. (2007). Nature and control of "dust storms" in the Beijing-Tianjin region, China - a case study of the dust storm in Beijing on April 16, 2006. The Bulletin of Geology, 26, 117-127.

IARC (1987). IARC Monographs on the evaluation of the carcinogenic risk of chemicals to humans-Overall evaluations of carcinogenicity: An updating of IARC monographs, vols. 1-42, Suppl. 7. Lyon: IARC.

Jaga, K., \& Dharmani, C. (2003). Global surveillance of DDT and DDE levels in human tissues. Int. Journal of Occupational Medicine and Health, 16, 7-20.

Kabbany, S. E., Rashed, M. M., \& Zayed, M. A. (2000). Monitoring of the pesticide levels in some water supplies and agricultural land in ElHaram, Giza. Journal of Hazardous Materials, 72, 11-21.

Kawano, M., Ramesh, A., Thao, V. D., \& Tatsukawa, R. (1992). Persistent organochlorine insecticide residues in some paddy, upland and urban soils of India. International Journal of Analytical Chemistry, 48, 163-174.

Kim, S. K., Oh, J. R., Shim, W. J., Lee, D. H., Yim, U. H., Hong, S. H., et al. (2002). Geographical distribution and accumulation features of organochlorine residues in bivalves from coastal areas of South Korea. Marine Pollution Bulletin, 45, 268-279.

Li, G., Zhang, G., Guo, L., Xu, W., Li, X., Lee, C. S. L., et al. (2007). Organochlorine pesticides in the atmosphere of Guangzhou and Hong Kong: Regional sources and longrange atmospheric transport. Atmospheric Environment, 41, 3889-3903.

Lin, Y. S., Gong, R. Z., \& Zhu, Z. L. (2000). Pesticides and ecoenvironmental protection. Beijing: Chemical Industry Press.
Lin, Y. W., \& Chen, Y. L. (2007). The price of global warming. Global Business, 6, 86-87.

Ma, L. L., Chu, S. G., \& Xu, X. B. (2003). Organic contamination in the greenhouse soils from Beijing suburbs, China. Journal of Environmental Monitoring, 5, 786-790.

Ma, L. L., Muir, D., Wang, X. T., \& Xu, X. B. (2005). Simultaneous analysis of organic pollutants in soils by gas chromatography and gas chromatography mass spectrometry. International Journal of Environmental Analytical Chemistry, 85, 89-98.

Madrid, L., Diaz-Barrientos, E., \& Madrid, F. (2002). Distribution of heavy metal contents of urban soils in parks of Seville. Chemosphere, 49, 1301-1308.

Mielke, H. W., Gonzales, C. R., Smith, M. K., \& Mielke, P. W. (1999). The urban environment and children's health: Soils as an integrator of lead, zinc and cadmium in New Orleans, Louisiana, USA. Environmental Research, 81, $117-129$.

Minh, N. H., Minh, T. B., Kajiwara, N., Kunisue, T., Subramanian, A., Iwata, H., et al. (2006). Contamination by persistent organic pollutants in dumping sites of Asian developing countries: Implication of emerging pollution sources. Archives of Environmental Contamination and Toxicology, 50, 474-481.

Qiu, X., Zhu, T., Li, J., Pan, H., Li, Q., Miao, G., \& Gong, J. (2004). Organochlorine pesticides in the air around the Taihu Lake, China. Environmental Science \& Technology, 38, 1368-1374.

Qiu, X., Zhu, T., Yao, B., Hu, J., \& Hu, S. (2005). Contribution of dicofol to the current DDT pollution in China. Environmental Science \& Technology, 39, 4385-4390.

Rauf, V. G., Vladimir, N. B., \& Rosa, A. G. (2002). Behavior of persistent organic pollutants in the air-plant-soil system. Water, Air, and Soil Pollution, 137, 179-191.

UNEP (1998). Preparation of an internationally legally binding instrument for implementing international action on certain persistent organic pollutants; UNEP/POPS/ Inc.1/6. Nairobi: United Nations Environment Programme.

Wang, S. G., Wang, J. Y., Zhou, Z. J., Shang, K. Z., Yang, D. B., \& Zhao, Z. S. (2003). Regional characteristics of dust events in China. Acta Geographica Sinica, 58, 193-200.

Wania, F., \& Mackay, D. (1995). Trading the distribution of persistent organic pollutants. Environmental Science \& Technology, 30, 390-396.

WHO (2000). Air quality guidelines for Europe, second ed. WHO Regional Publications, Eur. Series No. 91. Copenhagen: World Health Organization, Regional Office for Europe.

Zhang, Z. L., Huang, J., Yu, G., \& Hong, H. S. (2004). Occurrence of PAHs, PCBs and organochlorine pesticides in Tonghui River of Beijing, China. Environmental Pollution, 130, 249-261.

Zhang, H., Lu, Y., Dawson, R. W., Shi, Y., \& Wang, T. (2005). Classification and ordination of DDT and $\mathrm{HCH}$ in soil samples from the Guanting Reservoir, China. Chemosphere, 60, 762-769.

Zhao, Y. W., Chen, K., Ma, X. Y., \& Yao, K. Y. (2002). A study on the residue of the organochloride pesticides in soils and rice. Zhejiang Preventive Medicine, 14, 1-3. 